\title{
Microorganisms Resistance Pattern and Antibiotic Prescriptions in Patients Admitted to the Intensive Care Unit in Ghazy AL Hariri Hospital
}

\author{
Laith G. Shareef ${ }^{1}$, Ayad Abbas Salman², Mohammed A. Taher ${ }^{3}$ \\ ${ }^{1}$ Clinical Pharmacist, Clinical Pharmacy Department, Medical City, Baghdad,Iraq, ${ }^{2}$ Professor, Chairman of \\ the Scientific Council of Anesthesia and Intensive Care/Iraqi Board, Baghdad, Iraq, ${ }^{3}$ Professor, The OsolAldeen \\ Private University College, Baghdad, Iraq
}

\begin{abstract}
Introduction: Resistance to antibiotics has emerged recently due to the misuse of antibiotics and is a threat to the health-care system, especially in developing countries like Iraq where there are no antimicrobial stewardship programs in most intensive care units (ICU).

Materials and Method: This was anobservational, cross-sectional study done in the ICU of Ghazi AL Hariri hospital, Medical City/Iraq. All patients getting admitted to ICU from both genders were included in the study.Samples taken for culture and sensitivity tests included blood, urine, tracheostomy tube, sputum, cerebrospinal fluid, central venous line, and bedsore swab.

Results: 43 patients satisfied the inclusion and exclusion criteria and were included in the study. The most common isolated pathogens were pseudomonas in sputum and blood samples, Acinetobacter in wounds and operation skin site infection, Klebsiella in central venous line, and bedsore swab, while Candida in the urine. Klebsiella was the most frequently isolated in overall culture results, it was most sensitive to imipenem, meropenem, and amikacin.

Conclusion: Ceftriaxone was the most commonly used antibiotic as an empiric treatment followed by meropenem and amikacin. Most of the isolated pathogens (>90\%) had resistance to ceftriaxone. ICUacquired Klebsiella, P. aeruginosa, and Acinetobacter predominate hospital-acquired infections.
\end{abstract}

Keywords: Intensive care unit, Microorganisms resistance, Antibiotics.

\section{Introduction}

Infections are a common cause of hospital admission, and hospital-acquired infections are an increasingly common condition, mainly within the acute/critical care setting ${ }^{[1]}$. Incidence of hospitalacquired infections in the Intensive Care Unit (ICU) has been stated to be about $2-5$ times greater than in

\section{Corresponding Author:}

\section{Laith G. Shareef}

Clinical Pharmacist, Clinical Pharmacy Department,

Medical City, Baghdad, Iraq

Mobile No.: 009647702884263

e-mail: laithalkunani@yahoo.com the general inpatient hospital residents. These infections add considerable costs, morbidity, and mortality to the patients. The epidemiology, microbiology, and impact of ICU-acquired infections such as ventilator-associated pneumonia (VAP), catheter-associated urinary tract infections, and catheter-related bloodstream infections have been comprehensively studied and reported in the western literature ${ }^{[2]}$, There is growing evidence to propose that rates of ICU-acquired infections might even be more significant in developing countries ${ }^{[3]}$. ICU is a center for the development of antibiotic-resistant Gramnegative bacteria, and multi-resistant Gram-positive infections, since of high degrees of antibiotic usage, quick patient turnover, the immunological vulnerability of acutely ill patients, and recurrent interaction between healthcare staffs and patients, enabling cross- 
transmission. Antibiotic stewardship programs are considered essential to reduce antibiotic resistance ${ }^{[4],[5]}$. There is inadequate literature concerning common ICUacquired infections in the Iraqi setting, and therefore, western guidelines are deduced for the treatment of these infections. The localdistinctions in the incidence, microbiology, and resistance patterns within Iraq are not well documented yet. Local guidelines for the prevention and treatment of these infections cannotbe made without a properassessment of theregion-specific study.Hereafter, we sought to perform a cross-sectional, prospective data collection evaluating the microbiology, resistance patterns, and outcomes of ICU infections. Although the developments in modern medicine and intensive care, the rate of sepsis in intensive care units (ICUs) remains high. In a global study of 1265 ICUs, $60 \%$ of ICU patients at the period of the study were considered infected, with infection found to be a strong independent predictor for mortality ${ }^{[6]}$. The threats of infection in general and with a resistant pathogen in particular, increased with the interval of patient stay in the ICU. Several influences contribute to the elevated incidence of these infections in the ICU and the related poor patient outcomes, in comparison with patients in different hospital wards, patients in ICUs have more chronic comorbid diseases and more acute physiologic instabilities and thus are relatively immunosuppressed ${ }^{[7]}$.

\section{Materials and Method}

This was a hospital-based observational, crosssectional study done in the intensive care unit (ICU) of Ghazi AL Hariri hospital, Medical city/Baghdad, Iraq during the period from $1^{\text {st }}$ October 2018 to the $1^{\text {st }}$ of August 2019. All patients getting admitted to ICU from both genders with different infections will include in the study. Demographic details, comorbidities, duration of ICU admission, number of antibiotics used, antibiotic prescription, antimicrobial resistance pattern of patients will be collected.patients who are HIV positive, who could not provide an adequate specimen, and patients who died within $48 \mathrm{~h}$ after admission, patient with incomplete data. Since most of the patients were incapable of talking, because of being critically ill or intubated (by endotracheal tube or tracheostomy), data collection mainly from patients' case files and unit's staff (doctors, nurses, pharmacists, and lab technicians). Samples taken for culture and sensitivity tests included blood, urine, tracheostomy tube, sputum, cerebrospinal fluid, central venous line, and bedsore swab.
Statistical Analysis: Data of 43 cases and 430 samples collected from the admitted patients analyzed by using the statistical package for social sciences (SPSS) software version 23, IBM, Chicago, US, for windows. Descriptive statistics presented as mean, frequencies, and proportion (\%). Finally, results are presented in tables and or figures with an explanatory paragraph.

\section{Results}

Throughout the study period, 105 patients admitted to ICU were enrolled, 62 of them excluded from the study, 43 patients satisfied inclusion and exclusion criteria, and included in the study. The mean age of the study population was $50.72 \pm 20.73$ and of whom $23(52.30 \%)$ were men, and $20(46.5 \%)$ were females. From the 43 participants $23(53.5 \%)$ survived and 20 (46.5\%) died. The most common admitted cases to the ICU was stroke representing (20.9\% [9/43]), postoperative cases (18.6\% [8/43]). The duration of hospitalization was between $2-180$ days. The mean duration of admission was 22.38 ( $\mathrm{SD} \pm 15.4$ ) days. The outcome of the admitted patients was as follows: 20 patients went back to their original wards to finalized their therapies, three patients discharged home. Twenty patients died (mortality rate of $46.5 \%$ ). All patients received pharmacological treatments regarding their conditions, involving empirical antibiotics depending on the physician's opinion about the clinical state of the patient. The mean period for empiric treatment was $5.67(\mathrm{SD} \pm 4.92)$ days, the empirical antibiotics used in variable combinations considering the patient's condition; ceftriaxone was the most commonly used antibiotic as an empiric treatment (39.7\%) followed by meropenem (23.5\%) and amikacin (5.9\%) (Table 1).

Table 1: Antibiotics used for empiric treatment.

\begin{tabular}{|l|c|c|}
\hline Antibiotic & Frequency & Percent \\
\hline Ceftriaxone & 27 & 39.7 \\
\hline Meropenem & 16 & 23.5 \\
\hline Amikacin & 4 & 5.9 \\
\hline Piperacillin/Tazobactam & 3 & 4.4 \\
\hline Levofloxacin & 3 & 4.4 \\
\hline Metronidazole & 3 & 4.4 \\
\hline Ciprofloxacin & 2 & 2.9 \\
\hline Imipenem & 2 & 2.9 \\
\hline Vancomycin & 2 & 2.9 \\
\hline Amoxicillin & 2 & 2.9 \\
\hline
\end{tabular}




\begin{tabular}{|l|c|c|}
\hline Antibiotic & Frequency & Percent \\
\hline Amoxicillin/Clavulanic acid & 1 & 1.5 \\
\hline Ceftazidem & 1 & 1.5 \\
\hline Azithromycin & 1 & 1.5 \\
\hline Linezolide & 1 & 1.5 \\
\hline Total & $\mathbf{6 8}$ & $\mathbf{1 0 0 . 0}$ \\
\hline
\end{tabular}

The antibiotics, as mentioned earlier used as a single agent or in combinations of two or three agents according to the patient's status, $48.8 \%$ of the patients given a combination of two or more antibiotics. All patients underwent culture and sensitivity (CS) test as soon as they were admitted to the ICU, the meantime needed for CS test results to return to the ICU was 10 $(\mathrm{SD} \pm 5.1)$ days, range $(2-25)$ days. In most of the cases, the antibiotics changed according to the results of the bacteriological test. Samples obtained for CS tests included blood, sputum, urine, tracheostomy tube, central venous line, foley catheter tip, and bedsores. The number of positive cultures and sensitivity test results obtained in 327 samples out of a total of 430 tests. The most common isolated pathogen was summarized in Figure (1).

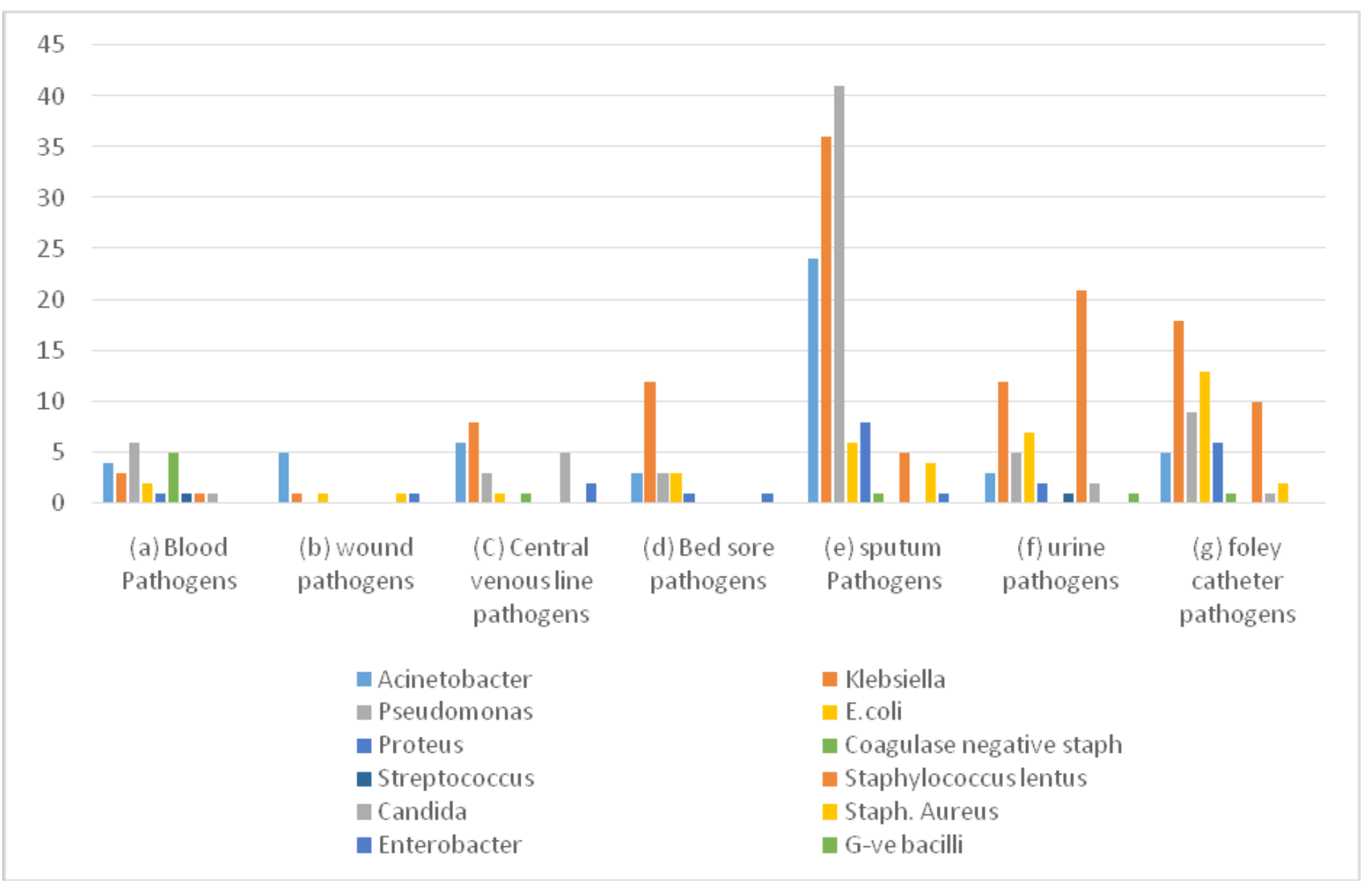

Figure 1: (a) blood cultures pathogens (b) wound swab pathogens (c) central venous line pathogens (d) bedsore pathogens(e) sputum cultures pathogens (f) urine cultures pathogens (g) Foley catheter cultures pathogens.

In overall culture results in a total of 327 tests the most frequently isolated pathogens were Klebsiella $27.5 \%$ (90/327), followed by Pseudomonas 20.5\% (67/327) and Acinetobacter 15.3\% (50/327) Table (2). 
Table 2: The frequency and percentage of isolated pathogens in cultures and sensitivity tests

\begin{tabular}{|c|c|c|c|}
\hline \multicolumn{2}{|c|}{ Pathogens } & \multirow{2}{*}{$\begin{array}{c}\text { Frequency } \\
90\end{array}$} & \multirow{2}{*}{$\begin{array}{c}\text { Percent } \\
27.5\end{array}$} \\
\hline \multirow{13}{*}{ Valid } & Klebsiella & & \\
\hline & Pseudomonas & 67 & 20.5 \\
\hline & Acinetobacter & 50 & 15.3 \\
\hline & Candida & 42 & 12.8 \\
\hline & E.coli & 33 & 10.1 \\
\hline & Proteus & 18 & 5.5 \\
\hline & Enterobacter & 10 & 3.1 \\
\hline & Coagulase -ve staphylococcus & 7 & 2.1 \\
\hline & Staphylococcus aureus & 5 & 1.5 \\
\hline & Streptococcus & 2 & .6 \\
\hline & Gram -ve bacilli & 1 & .3 \\
\hline & Burkholderiacepacia & 1 & .3 \\
\hline & Total & 327 & 100.0 \\
\hline
\end{tabular}

These microorganisms tested for their sensitivity to several antimicrobial kits to about 30 antibiotics. From the results of Klebsiella sensitivity tests, there are only 188 time-sensitive results of the tested antibiotics (about
30) for a total of 90 times detected positive culture tests. Klebsiella Pneumonia was most commonly sensitive to imipenem 55\% (50/90), followed by meropenem $30 \%$ (27/90), and amikacin 26.6\% (24/90) Figure (2).

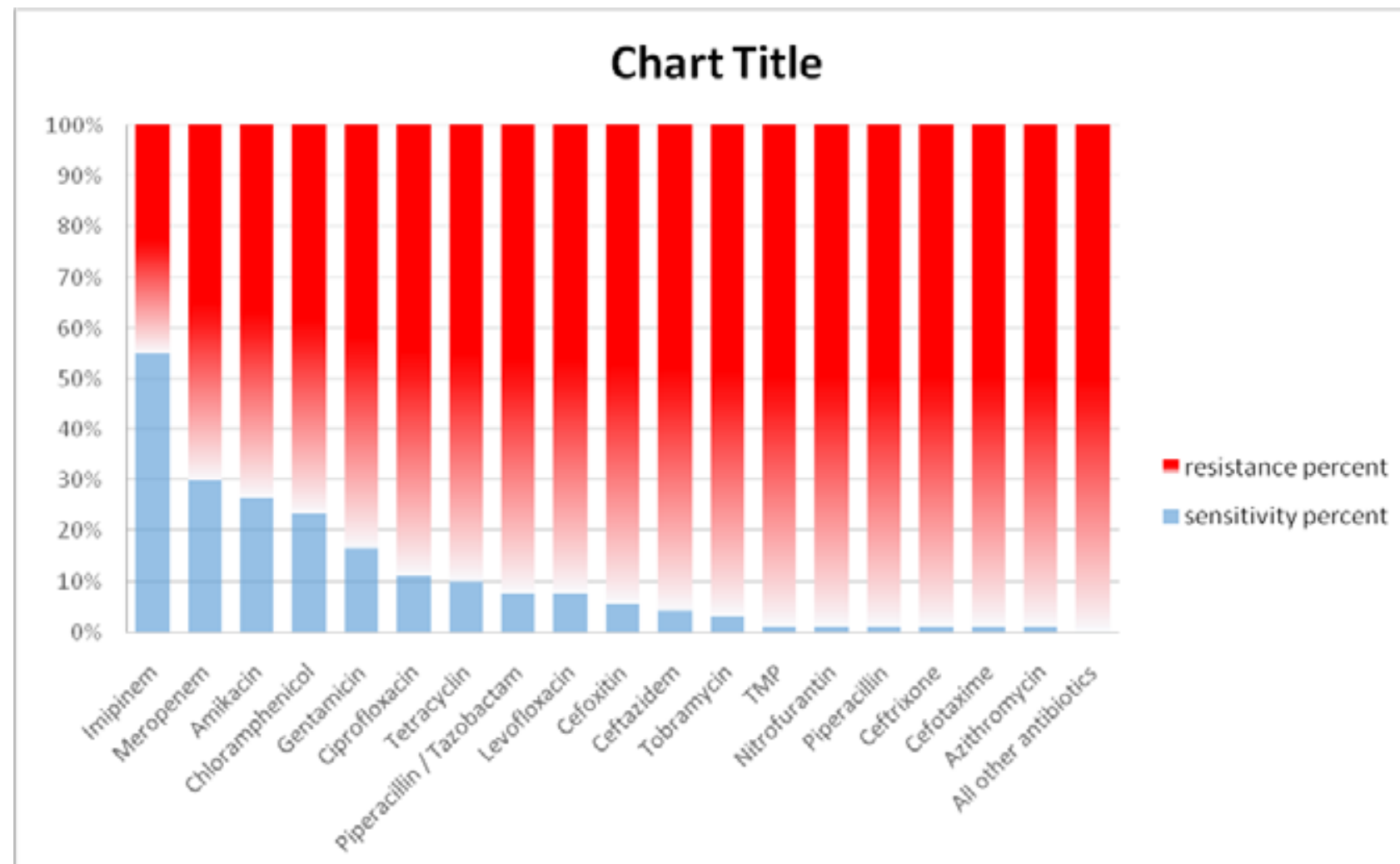

Figure (2): Percent of Klebsiella pneumonia sensitivity and resistance to antibiotics 
In regards to Pseudomonas which they reported positively in 67 tests, it showed sensitivity to piperacillin/ tazobactam in $43.2 \%$, imipenem $35.5 \%$, ceftazidime $31.3 \%$ Figure (3).

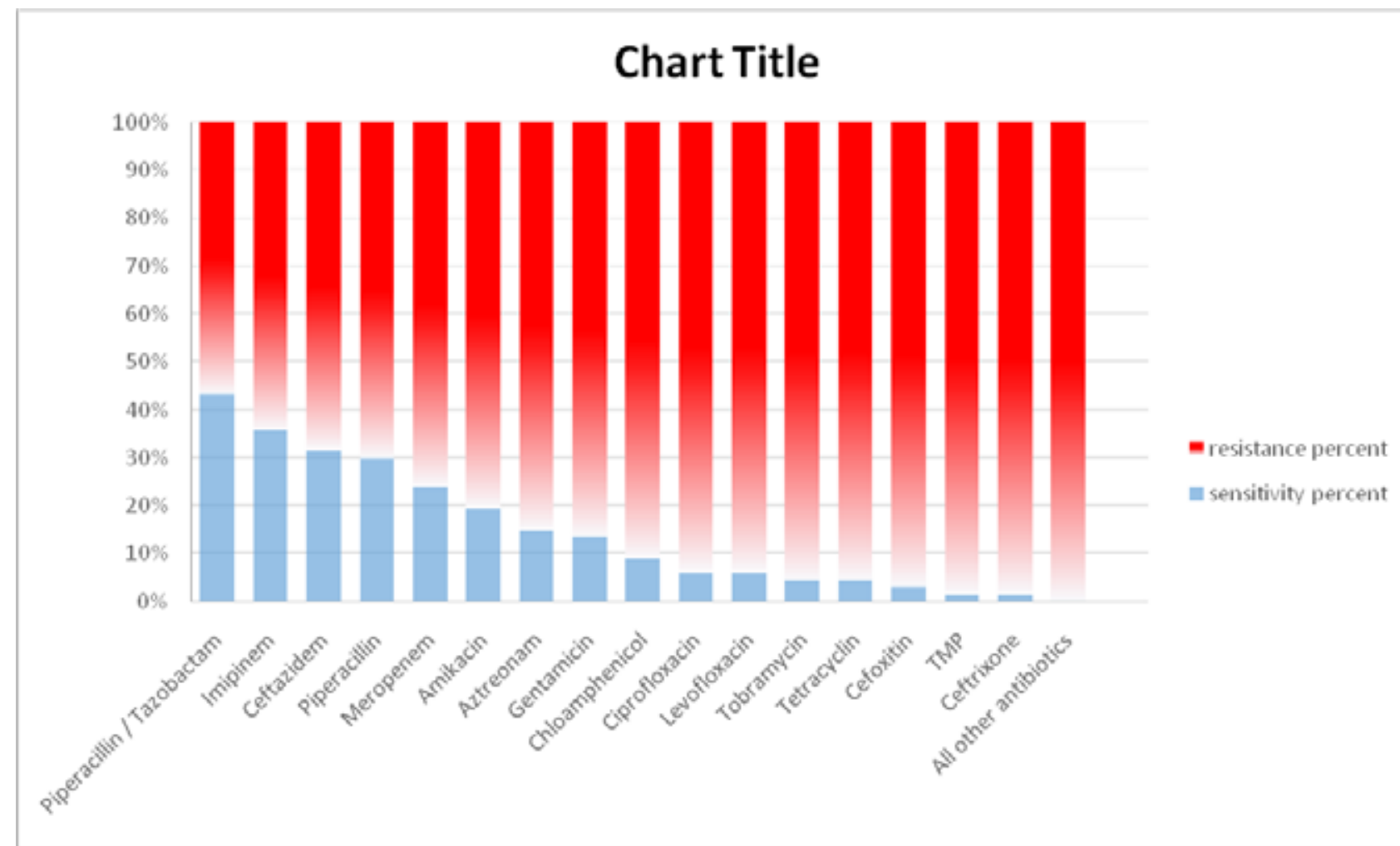

Figure (3): Percent of Pseudomonas aeruginosa sensitivity and resistance to antibiotics

Acinetobacter bumani which was isolated in $15.5 \%$ of all positive results showed sensitivity to amikacin in $22 \%$, tetracyclin in $18 \%$, ampicillin, gentamicin, tobramycin, imipenem were $14 \%$ for each one, Figure (4).

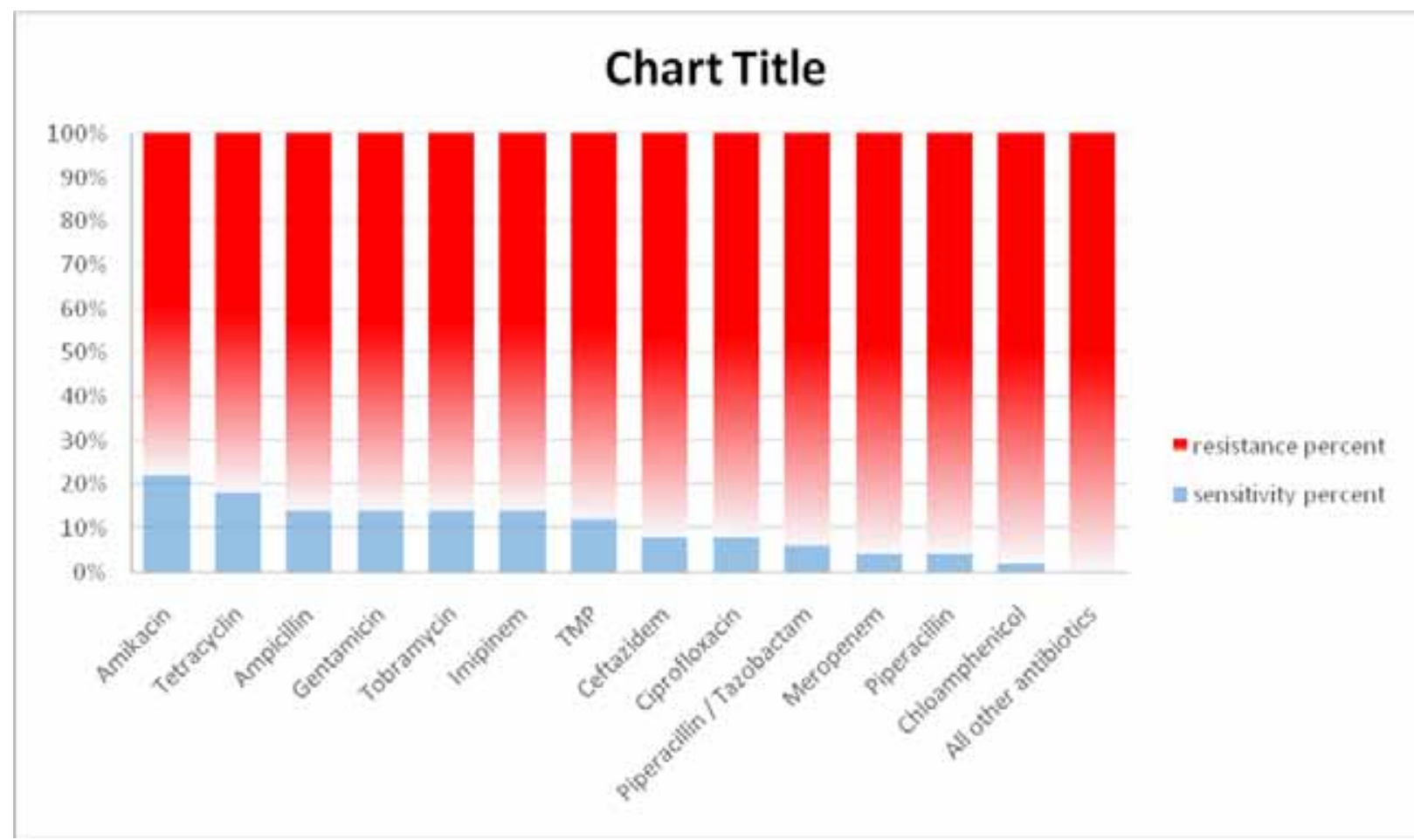

Figure (4): Percent of Acinetobacter bumanisensitivity and resistance to antibiotics 
Proteus showed sensitivity in to piperacillin/ tazobactam $61.1 \%$, imipinem $55.5 \%$, ciprofloxacin $44.4 \%$, meropenem 44.4\%, amikacin $38.8 \%$, ceftazidem $33.3 \%$, gentamicin $33.3 \%$, cefoxitin $22.2 \%$, cefotaxime $22.2 \%$, chloamphenicol $16.6 \%$, ceftrixone $16.6 \%$, aztreonam $11.1 \%$, amoxicillin/clavulanic acid $11.1 \%$, TMP $11.1 \%$, piperacillin $5.5 \%$, and levofloxacin $5.5 \%$.

E. coli was sensitive to imipenem in $60.6 \%$, chloramphenicol $36.6 \%$, and $33.3 \%$ sensitive to meropenem, amikacin $30.3 \%$, ciprofloxacin $21.2 \%$, Piperacillin/Tazobactam $21.2 \%$, gentamicin $18.1 \%$, nitrofurantin $18.1 \%$, levofloxacin $9 \%$, tetracyclin $9 \%$, ceftazidem $6 \%$, cefoxitin $6 \%$, ampicillin, aztreonam, tobramycin, ceftriaxone and cefotaxime $3 \%$. Streptococcus pneumonia was sensitive only in two times, once for tetracycline and the second for trimethoprimsulfamethoxazole. Enterobacter was sensitive for chloramphenicolin $40 \%$, Ciprofloxacinin $30 \%$, Imipenem in $20 \%$, and $10 \%$ for each aztreonam, levofloxacin, tetracycline. Staphylococcus aureus was sensitive to chloramphenicol in 50\%, 30\% to vancomycin, and $20 \%$ to trimethoprim-sulfamethoxazole. Coagulase-negative staphylococcus was $100 \%$ sensitive to Vancomycin, tetracyclin in $42 \%$, gentamicin \& nitrofurantoin in $28 \%$, and chloramphenicol 14\%. Candida Albicans was the most isolated fungi it was sensitive 6 times to miconazole, 5 times for both fluconazole and ketoconazole. Staphylococcus lentusis isolated in one case of sepsis. Overall bacterial sensitivity between the tested antibiotics showed $17.7 \%$ to imipenem, amikacin, and meropenem $10.2 \%$. Table (3).

Table (3): Overall bacterial sensitivity to antibiotics in the 327 positive culture tests

\begin{tabular}{|c|c|c|c|}
\hline \multicolumn{2}{|c|}{ Tested Antibiotics } & \multirow{2}{*}{$\begin{array}{c}\text { Frequency } \\
113\end{array}$} & \multirow{2}{*}{$\begin{array}{c}\text { Percent } \\
34.5\end{array}$} \\
\hline \multirow{22}{*}{ Valid } & Imipinem & & \\
\hline & Amikacin & 65 & 19.8 \\
\hline & Meropenem & 65 & 19.8 \\
\hline & Piperacillin/Tazobactam & 57 & 17.4 \\
\hline & Chloramphenicol & 53 & 16.2 \\
\hline & Gentamicin & 45 & 13.7 \\
\hline & Ceftazidem & 38 & 11.6 \\
\hline & Ciprofloxacin & 36 & 11 \\
\hline & Tetracyclin & 29 & 8 \\
\hline & Piperacillin & 24 & 7.3 \\
\hline & Levofloxacin & 16 & 4.8 \\
\hline & Aztreonam & 14 & 4.2 \\
\hline & TMP & 14 & 4.2 \\
\hline & Tobramycin & 14 & 4.2 \\
\hline & Cefoxitin & 13 & 3.9 \\
\hline & Vancomycin & 10 & 3 \\
\hline & Nitrofurantoin & 9 & 2.7 \\
\hline & Ampicillin & 8 & 2.4 \\
\hline & Ceftriaxone & 7 & 2.1 \\
\hline & Cefotaxime & 6 & 1.8 \\
\hline & Amoxicillin/Clavulanic acid & 2 & 0.6 \\
\hline & Azithromycin & 1 & 0.3 \\
\hline
\end{tabular}


Also, there are samples taken as a swab from the beds, ventilator machines, oxygen suppliers, fluid stands, floors, walls. coagulase-negative staphylococcus was the most frequently isolated pathogen followed by bacillus species.

\section{Discussion}

In the current study each patient with a documented or a suspected source of infection received antibiotic prescription by the physician in charge, and generally, it is grounded on a clinical basis and experience.And this is whatfollowed in five tertiary carehospitals in Germany as mentioned by Wilke $\mathrm{M}$ et al. who stated that therapy grounded on local experiences might be appropriate for patients with low complicated pathogen risk score (CPRS) but insufficient for those with high $\mathrm{CPRS}^{[8]}$.As well, in the current study, the meantime for culture and sensitivity results to come back to ICU was very long, this is a time-consumingstep. This issue is also a challenge in therapeutic practice even in European countries.As there is a profound difference between countries in retrieving the results of the culture tests, for example in the United Kingdom, 2 hours are needed from collection to incubation while in Germany 20 hours are necessary for incubating the bacteria due to distant laboratories ${ }^{[9]}$, still, these times are much shorter than that in the settings followed in Ghazi Al Hariri center. Many studies are debating new method to reduce the period of detecting the causal organisms in the patients to enhance the choice of the antibiotics as early as possible and consequently improve the outcome.Such as a study thatemployeda new spectrometry method that provides rapid pathogen identification in critically ill patients with the capability to rule out infection within 6 hours. This has potential clinical and economic benefits ${ }^{[10]}$. In the present study, the most frequently isolated pathogen was Klebsiella pneumoniae, and the lowest isolation rate was for Burkholderiacepacia and Gram-negative bacilli. Causative organisms diverge in different geographical areas. This result is differing from that previously published in Asian countries, a study conducted in a tertiary teaching hospital of Eastern India intensive care unit which stated Pseudomonas is the most isolated microorganism while the lower isolation rate was for th eCoagulase-negative staphylococci, Enterobacter spp, Stenotrophomonas spp, Burkholderiacepacia ${ }^{[11]}$. In a study of Ghanshani et al. they found a higher rate of bacterial isolation for the following pathogens: Acinetobacter,Klebsiella, Streptococcus, Pseudomonas, and Staphylococcus ${ }^{[12]}$. Several studies from other
Asian countries such as Indonesia, Thailand stated that frequency of Pseudomonas isolation was about $(26 \%-$ $50 \%$ ) followed by Klebsiella and S. epidermidis ${ }^{[13,14]}$. In another study, done in Turkey showed that Pseudomonas spp. were the most frequently isolated Gram-negative spp., followed by Klebsiella spp. E. coli, Acinetobacter spp. And Enterobacter spp. were the other commonly isolated organisms ${ }^{[15]}$. Antimicrobial resistance is a major worldwide problem in ICU, including Iraq. ICUs are the main foci of antibiotic resistance within the hospital wards ${ }^{[16]}$.Antimicrobial resistance is emerging due to the deficiency of hospital hygiene and the misuse of antibiotics ${ }^{[17]}$. Antibiotic prescription in an ICU is mostly empirical and centered on previouspractices; hereafter, patients who gotimproper empirical antibiotic treatmentsignificantly increase hospital stay and increases mortality ${ }^{[18]}$ hospital-acquired infections originating from drug-resistant microorganisms further add to the existing problem. A striking outcome from this study was the degree of drug resistance among key pathogens. This study detected high drug resistance of Klebsiella to a commonly prescribed drug compared to a study done by Kumari et al. ${ }^{[19]}$, who observed similar levels.P. aeruginosa isolates showed a high rate of resistance to ceftriaxone, TMP, ciprofloxacin, levofloxacin, gentamicin, amikacin, the most effective antibiotics were piperacillin/tazobactam, imipenem, and ceftazidime. The similar result reported previously in a study by Radji et al. ${ }^{[20]}$ in which they stated P. aeruginosa isolates displayed a high rate of resistance tocefotaxime, cephalexin, and ceftriaxone. But in this study,amikacin was the most effective antibiotic, followed by imipenem, andmeropenem.Acinetobacter bumani is extremely resistant to antibiotics ${ }^{[21]}$. In this study, the resistance was higherin Acinetobacter than all of the other isolated pathogens. This is in concordance to what was reported by Tran et al. where they stated that acinetobacter was resistant to nearly all antibiotics. Staphylococcus lentus a zoonosis pathogen was reported for the first time as a cause of septic shock during the work on this research ${ }^{[22]}$. Proteus mirabilis showed marked resistance to commonly used antibiotics. In the European and North American Surveillance study by Mark et al. ${ }^{[23]}$ they reported the resistance profile of Proteus in the US, Canada, Italy, Germany, and France. The resistance rate was different from ours; ceftriaxone resistance was $(0.3 \%, 0 \%, 13.8 \%, 0 \%, 0 \%)$ in the US, Canada, Italy, Germany, and France respectively. On the other hand, E. coli showed high resistance to several broad-spectrum antibiotics, Best sensitivity results achieved by imipenem, 
chloramphenicol, and meropenem. In comparison to what reported previously in a study by Zhanel et al. ${ }^{[24]}$, E. coli showed no resistance to amikacin, meropenem, and tigecycline. In the current study, ceftriaxone was the main antibiotic used as an empiric treatment followed by meropenem, amikacin, and piperacillin/tazobactam. This may be due to the previous experience with these drugs, its availability, its opened dispense with no limitation, and its broad spectrum of action. The infrequent use of chloramphenicol may explain its probable activity against isolated pathogens as shown by culture studies, and this, in turn, should alert the clinicians in charge (physician and the clinical pharmacists) to review their choices of the empirical therapy medications and to reduce their use of ceftriaxone as first choice antibiotic in the empirical management.Source of infections seem to be from the ICU equipment like the ventilator, sucker, fluid stands, and oxygen suppliers. Also, the wall, floor, and patients bed showed colonization with different microorganisms; Coagulase -ve staphylococcus and Bacillus spp were the most predominant pathogens. This is the leading cause of secondary endogenous infections and exogenous infection. It accounts for more than one-third of all types of ICU infections according to what reported in a study by Mukhopadhyay ${ }^{[25]}$. Ceftriaxone resistance was noted by Tran et al. who studied the resistance of bacteria in ICU against several antimicrobials and showed that most of Acinetobacter, Klebsiella, and Pseudomonas were resistant to ceftriaxone.

\section{Conclusion}

This study concluded that ICU-acquired Klebsiella, P. aeruginosa, and Acinetobacter predominate hospitalacquired infections. More disturbingly, all of them were multiple-drug resistant. The result here supports the view that multidrug resistance is a global public health threat, and highlights the need to study combined therapies and rational treatment strategies. Ceftriaxone was the most common empirical antimicrobial prescribed to patients admitted to ICU. Most of the isolated pathogens $(>90 \%)$ had resistance to it. Suitable antibiotic employment in ICU is crucial not only in guaranteeing the best outcome but also in inhibiting the development of multidrugresistant bacteria.

Ethical Approval: The study protocol approved by the Scientific Council of the Iraqi Board of Medical Specialization.

Conflict of Interest: Nil

\section{Funding: Nil}

\section{References}

1. Magill SS, Edwards JR, Bamberg W, Beldavs ZG, Dumyati G, Kainer MA, et al. Multistate point-prevalence survey of health care-associated infections. The New England journal of medicine 2014; 370(13):1198-1208.

2. Venkataraman R, Divatia JV, Ramakrishnan N, Chawla R, Amin P, Gopal P, et al. Multicenter Observational Study to Evaluate Epidemiology and Resistance Patterns of Common Intensive Care Unit-infections. Indian J Crit Care Med 2018; 22(1):20-26.

3. Rosenthal VD, Maki DG, Salomao R, Moreno CÁ, Mehta Y, Higuera F, et al. Device-associated nosocomial infections in 55 intensive care units of 8 developing countries. 2006; 145(8):582-591.

4. Van Duijn PJ, Bonten MJ. Antibiotic rotation strategies to reduce antimicrobial resistance in Gram-negative bacteria in European intensive care units: study protocol for a cluster-randomized crossover controlled trial. Trials 2014; 15:277.

5. Dong H, Wang X, Dong Y, Li H, You H, Wang M, et al. Clinical pharmacokinetic/pharmacodynamic profile of linezolid in severely ill intensive care unit patients. 2011; 38(4):296-300.

6. Vincent JL, Rello J, Marshall J, Silva E, Anzueto $A$, Martin $C D$, et al. International study of the prevalence and outcomes of infection in intensive care units. Jama 2009; 302(21):2323-2329.

7. Hynes-Gay P, Lalla P, Leo M, Merrill-Bell A, Nicholson M, Villaruel E. Understanding sepsis: from SIRS to septic shock. Dynamics (Pembroke, Ont) 2002; 13(1):17-20, 22-14; quiz 25-16.

8. Wilke M, Grube RF, Bodmann KF. Guidelineadherent initial intravenous antibiotic therapy for hospital-acquired/ventilator-associated pneumonia is clinically superior, saves lives and is cheaper than non guideline adherent therapy. European journal of medical research 2011; 16(7):315-323.

9. Schmitz RP, Keller PM, Baier M, Hagel S, Pletz MW, Brunkhorst FM. Quality of blood culture testing - a survey in intensive care units and microbiological laboratories across four European countries. Critical care (London, England) 2013; 17(5):R248. 
10. Vincent JL, Brealey D, Libert N, Abidi NE, O'Dwyer M, Zacharowski K, et al. Rapid Diagnosis of Infection in the Critically Ill, a Multicenter Study of Molecular Detection in Bloodstream Infections, Pneumonia, and Sterile Site Infections. Critical care medicine 2015; 43(11):2283-2291.

11. Dasgupta S, Das S, Chawan NS, Hazra A. Nosocomial infections in the intensive care unit: Incidence, risk factors, outcome and associated pathogens in a public tertiary teaching hospital of Eastern India. Indian J Crit Care Med 2015; 19(1):14-20.

12. Ghanshani R, Gupta R, Gupta B, Kalra S, Khedar R, Sood S. Epidemiological study of prevalence, determinants, and outcomes of infections in medical ICU at a tertiary care hospital in India. 2015; 32(5):441-448.

13. Radji M, Fauziah S, Aribinuko N. Antibiotic sensitivity pattern of bacterial pathogens in the intensive care unit of Fatmawati Hospital, Indonesia. Asian Pacific journal of tropical biomedicine 2011; 1(1):39-42.

14. Refdanita R, Radji M, Aribinuko N, Pauline EJMJoHR. The sensitivity pattern of microorganisms against antibiotics at the Intensive Care Unit of Fatmawati Hospital Jakarta 20012002. 2010:41-48.

15. Gunseren F, Mamikoglu L, Ozturk S, Yucesoy $\mathrm{M}$, Biberoglu K, Yulug N, et al. A surveillance study of antimicrobial resistance of gram-negative bacteria isolated from intensive care units in eight hospitals in Turkey. The Journal of antimicrobial chemotherapy 1999; 43(3):373-378.

16. Archibald L, Phillips L, Monnet D, McGowan JE, Jr., Tenover F, Gaynes R. Antimicrobial resistance in isolates from inpatients and outpatients in the United States: increasing importance of the intensive care unit. Clinical infectious diseases : an official publication of the Infectious Diseases Society of America 1997; 24(2):211-215.
17. Weinstein RAJEid. Controlling antimicrobial resistance in hospitals: infection control and use of antibiotics. 2001; 7(2):188.

18. Esposito S, Leone S. Antimicrobial treatment for Intensive Care Unit (ICU) infections including the role of the infectious disease specialist. International journal of antimicrobial agents 2007; 29(5):494-500.

19. Kumari HB, Nagarathna S, Chandramuki A. Antimicrobial resistance pattern among aerobic gram-negative bacilli of lower respiratory tract specimens of intensive care unit patients in a neurocentre. The Indian journal of chest diseases \& allied sciences 2007; 49(1):19-22.

20. Radji M, Fauziah S, Aribinuko N. Antibiotic sensitivity pattern of bacterial pathogens in the intensive care unit of Fatmawati Hospital, Indonesia. Asian Pacific journal of tropical biomedicine 2011; 1(1):39-42 .

21. Singh AK, Sen MR, Anupurba S, Bhattacharya P. Antibiotic sensitivity pattern of the bacteria isolated from nosocomial infections in ICU. The Journal of communicable diseases 2002; 34(4):257-263.

22. Shareef LG, Ali WI, Fawzi HA, Naser HAJMS. Staphylococcus Lentus as a cause of septic shock. 2019; 23(97):360-362.

23. Jones ME, Draghi DC, Thornsberry C, Karlowsky JA, Sahm DF, Wenzel RP. Emerging resistance among bacterial pathogens in the intensive care unit - a European and North American Surveillance study (2000-2002). Annals of Clinical Microbiology and Antimicrobials 2004; 3(1):14.

24. Zhanel GG, DeCorby M, Laing N, Weshnoweski $\mathrm{B}$, Vashisht $\mathrm{R}$, Tailor $\mathrm{F}$, et al. AntimicrobialResistant Pathogens in Intensive Care Units in Canada: Results of the Canadian National Intensive Care Unit (CAN-ICU) Study, 2005-2006. 2008; 52(4):1430-1437.

25. Mukhopadhyay C. Infection control in intensive care units. 2018; 7(1):14-21. 